\title{
NON-OPERATORS' RIGHTS UNDER THE CAPL OPERATING PROCEDURE
}

\author{
CLIFFORD D. JOHNSON*
}

This paper examines the major problems of the 1981 CAPL Operating Procedure relating to matters such as operatorship, costs and expenses, segregation of joint lands, relationship of the parties and independent operators. The primary perspective taken is that of the non-operator.

\section{INTRODUCTION}

The Canadian Association of Petroleum Landmen ("CAPL") form of operating procedure (the "operating procedure") as developed and amended periodically over the years represents the evolution of a standard form of agreement governing operations in circumstances where two or more parties, referred to as joint-operators, ' hold or come to hold joint interests in oil and gas properties. The operating procedure applies to oil and gas operations on lands made subject thereto, whether jointly acquired by the parties through Crown land sales or freehold acquisitions, or through farm-ins and the like. It is generally not intended to apply to production after severance from the ground, although some initial compressing, processing or treating at the well site may occur and be considered subject to the operating procedure. A notable exception occurs where certain joint-operators do not take their share of production in kind.

The operating procedure is generally appended to some form of head agreement, such as a farm-in agreement or joint operating agreement. This agreement may define the rights and obligations of the parties for the period of time until the operating procedure comes into effect or, in some cases, may modify or supplement the provisions of the operating procedure to meet the specific requirements of the parties. The CAPL 1974 Operating Procedure (the "1974 Procedure") gained fairly widespread acceptance during its tenure, as has its successor, the 1981 CAPL Operating Procedure (the "'1981 Procedure") currently in use. The 1981 Procedure is at present under review and is scheduled for replacement by the 1988 CAPL Operating Procedure (the "1988 Procedure') expected to be issued sometime in 1989. ${ }^{2}$ The various forms of operating procedures have embodied the central objective of CAPL to strike an appropriate balance between the interests of operators and those of non-operators without unduly interfering with matters of efficiency and convenience of operations. Achieving such a balance is not always an easy task.

* Partner, McCarthy \& McCarthy (formerly Black \& Company), located in Calgary. The author wishes to thank Kerry M. Smyth, Associate, McCarthy \& McCarthy, also located in Calgary, for her assistance in the preparation of this paper.

1. The operating procedure refers to the parties to the agreement (i.e. the operators and the non-operators), collectively as "joint-operators". In this paper the term joint-operators is used on the same basis. The term "non-operators" is used in reference to joint-operators other than the operator.

2. The amendments to the 1988 Procedure are under review by a CAPL committee as of this writing. The final form of the amendments and the issuing of the new procedure is expected to occur later this year. References to the proposed amendments in this paper will be to the draft provisions as at May 31, 1989. There is no certainty whether the amendments proposed will be made as drafted, or at all, and others may yet be proposed. 
The purpose of this paper is to examine, primarily from the perspective of the non-operator, the major provisions of the 1981 Procedure relating to matters such as operatorship, costs and expenses, segregation of joint lands, relationship of the parties and independent operations. Where appropriate, references will be made to the 1974 Procedure and the amendments currently proposed for the 1988 Procedure as well as the accounting procedures in use. It may be noted that there is very little case authority considering the provisions of the operating procedures such that many conclusions which may be reached are open to question and further interpretation by the courts.

\section{REVIEW OF THE RELEVANT PROVISIONS}

\section{A. OPERATORSHIP}

\section{Removal or Replacement of Operator}

One of the most basic and fundamental principles set forth in the 1981 Procedure, as with its predecessors, pertains to operatorship and the selection of one joint-operator to perform that role on behalf of all joint-operators. Conduct of operations in such a manner is obviously felt to be the most expedient for all concerned. It may be noted that this is not the usual approach for the operation of units or major facilities such as gas plants, where the operator conducts operations directly under the supervision of an operating committee comprised of representatives of the owners. This latter approach has the potential to give non-operators a more effective say in operations than that available to them under the operating procedure. However, the establishment of an operating committee for operations carried out under the operating procedure would be impractical in most circumstances, particularly where minimal lands are involved.

In the 1981 Procedure, the basic functions and duties of the operator are described in Article III, with the limitations on liability and the right of indemnification of the operator described in Article IV. Assuming the operator complies with its basic obligations, as set out in Clause 301 in particular, its ability to maintain its position as operator is virtually assured.

Substantial concems for non-operators arise in circumstances where it is believed that the operator is not adequately performing its obligations, or where the operator is in financial difficulty (with the attendant requirement of non-operators to nonetheless advance money to the operator to fund operations) or where the operator is receiving funds from third parties to which the non-operators are entitled. Moreover, the priorities for exploration and development of the joint lands may be different for the individual joint-operators at various times. When the attention of the operator is focused on other lands, or is otherwise disinterested or distracted from such matters, whether because of budgetary constraints, bankruptcy or insolvency or otherwise, the non-operators may feel a change of operators is appropriate. The non-operators face difficulties in effecting the removal of the operator if it chooses to resist such removal.

Under the 1981 Procedure there is a limited range of options available to the non-operators in this regard. The applicable provisions are set forth in Article II, entitled "Appointment and Replacement of Operator". Clause 202 is of potential application in the aforementioned situations. However, as straightforward as 
its provisions appear, their application is not without difficulty. Under Paragraph 202(a), the operator is to be replaced immediately in any one of the following circumstances:

(i) if the operator becomes bankrupt or insolvent or commits or suffers any act of banknuptcy or insolvency, or makes any assignment for the benefit of its creditors, or causes any judgment to be registered against its participating interest;

(ii) if the operator assigns or purports or attempts to assign its general powers and responsibilities of supervision and management as operator hereunder.

The first situation appears to be relatively straightforward, but this has not proven to be the case in practice. The terms "bankruptcy" and "insolvency" are undefined in the 1981 Procedure. They are often used synonymously, although perhaps incorrectly, as the "inability to pay one's debts" ${ }^{3}$ Nonetheless, the legal status of a person in each case is quite different. Since the Bankruptcy $\mathrm{Act}^{4}$ is a codification of the common law of bankruptcy and insolvency, its provisions would seem to be appropriate for the interpretation that the provisions of an agreement that reflect an intention that they apply. It is submitted that the framers of the 1981 Procedure and its predecessors evidenced such an intention through utilizing the appropriate terminology.

A "bankrupt" is defined in section 2 of the Bankruptcy Act as "a person who has made an assignment or against whom a receiving order has been made or the legal status of that person". An "assignment" is effected by the voluntary application of an "insolvent person" to the provisions of the Bankruptcy Act by making an assignment for the benefit of his creditors. If all the formalities are met and the assignment is filed with the official receiver, it becomes an official record of the court. A "receiving order" is an order made in respect of a person who is involuntarily petitioned into bankruptcy by one or more creditors. ' Under subsection 71(1) of the Bankruptcy Act, ${ }^{8}$ the "bankruptcy" is deemed to have commenced upon a receiving order being made or an assignment being filed with the official receiver. ${ }^{9}$ Whether or not an assignment or receiving order has been made by or in respect of an operator is a question of fact. If it has occurred in respect of an operator, such operator is subject to "immediate replacement".

An "insolvent person" is defined in the Bankruptcy Act ${ }^{10}$ to mean " a person who is not bankrupt and who resides or carries on business in Canada, whose liabilities to creditors provable as claims under this Act amount to one thousand dollars, and:11

(a) who is for any reason unable to meet his obligations as they generally become due,

(b) who has ceased paying his current obligations in the ordinary course of business as they generally become due, or

3. Black's Law Dictionary, Sth ed. (St. Paul: West Publishing, 1979) at 134 and 716.

4. Bankruptcy Act, R.S.C. 1985, c. B-3.

5. Ibid.

6. Ibid.

7. Ibid., subsection 43(1).

8. Supra, note 4.

9. See for example, Re Bad Boy Mobile Homes Ldd., 22 C.B.R. (N.S.) 14, [1976] 3 W.W.R. 590 , 66 D.L.R. (3d) 324 (B.C. Sup. Ct.); Re McAulay Bros. Ld.; Broadhead v. Royal Bank of Canada, 12 C.B.R. (N.S.) 94, [1968] 2 O.R. 717, 70 D.L.R. (2d) 445 (H.C.).

10. Supra, note 4 .

11. Ibid., section 2 . 
(c) the aggregate of whose property is not, at a fair valuation, sufficient, or, if disposed of at a fairly conducted sale under legal process, would not be sufficient to enable payment of all his obligations, due and accruing due;"

This definition is consistent with the import of the common law definition noted above, namely that such a person is unable to pay its debts. However, there is an added prospective element described in subsection (c) above which may not have been caught by the common law definition. It is a "liquidation value" test which would be difficult to assess in any given circumstances with any degree of certainty.

If an actual bankruptcy has not yet occurred, and it is unclear whether or not an insolvency exists, the next determination to be made in respect of the potential application of Paragraph 202(a) is whether or not the operator has committed or suffered any "act of bankruptcy or insolvency". The references to acts of bankruptcy or insolvency appear to refer to the situation where a person has committed an act of bankruptcy, but has not yet been rendered (either voluntarily or involuntarily) subject to the Bankruptcy $A c t,{ }^{12}$ with the resultant status of a bankrupt or insolvent person. Subsection 42(1) of the Bankruptcy Act $t^{13}$ lists ten situations in which a debtor is deemed to have committed an act of bankruptcy. The most notable for present purposes is as set forth in Paragraph 42(1)(j), which applies to a person "if he ceases to meet his liabilities generally as they become due". The supplementary words "or makes any assignment for the benefit of its creditors" in Paragraph 202(a) of the 1981 Procedure are somewhat superfluous in that such an event would in and of itself constitute an act of bankruptcy under the Bankruptcy Act. ${ }^{14}$

The last element of Sub-paragraph 202(a)(i) of the 1981 Procedure of potential application is where the operator causes any judgment to be registered against its participating interest. ${ }^{15}$ It is questionable whether the filing of a judgment is an appropriate event to trigger a change in operatorship, since the judgment could affect or relate to only a portion of the lands and a minor share of the relevant participating interests. Further, it could apply only to a "carved out" interest, rather than to the entire or even a portion of the relevant working interest. However, a nonoperator having found a writ of execution filed against the title to the lands as a result of a judgment against the operator would appear to have found the grounds to have the operator removed, although it is highly unlikely that such an operator would voluntarily resign.

Even if, in the particular circumstances, one could conclude that the operator is either bankrupt or insolvent, this conclusion will not necessarily determine the issue. A non-operator approaching the operator with the news that the operator is going to be replaced will often be invited to prove the bankruptcy or insolvency. In the case of a bankruptcy this may not be all that difficult as the appropriate searches ${ }^{16}$ would confirm that fact. However, in the case of insolvency, a great deal of information may be required to prove that the operator is in fact insolvent.

12. Supra, note 4.

13. Bbid.

14. Ibid. at Paragraph 42(1)(a).

15. "Participating interest" is defined in Paragraph 101(b) of the 1981 Procedure to be the percentage of undivided interest in the joint lands held by a party.

16. Such as those obtained from the Alberta Department of Consumer and Corporate Affairs, Office of the Official Receiver and the Court of Queen's Bench, Bankruptcy Division. 
In this latter circumstance, the non-operator may have no choice but to proceed with court action to effect removal of the operator if its cooperation in that regard is not forthcoming.

Assuming that the facts in support of a bankruptcy or insolvency are established, one could infer from the positive language of Clause 202 that the change of operator is to happen immediately upon such occurrence. There are three cases that have dealt with the issue of removal of the operator pursuant to the provisions of Article II of the 1981 Procedure, the Tri-Star case, ${ }^{17}$ the Oakwood case ${ }^{18}$ and the Rimoil case. ${ }^{19}$

In the Tri-Star case, ${ }^{20}$ the court was considering the rights of the parties under an operating agreement entered into among a number of companies in 1984 governing certain lands, to which the 1981 Procedure was appended. A proposal was made by J.C. International in July of 1986 under the Bankruptcy $A t^{21}$ and Mr. Justice Dixon granted an order on July 24th, 1986 appointing Clarkson Gordon Inc. as interim receiver. The plaintiffs Tri-Star and Copetrex each argued that, pursuant to the terms and conditions of their respective operating agreements, it was now the operator pro $\mathrm{tem}^{22}$ and sought a declaration naming it as operator. Mr. Chief Justice Moore noted that the Royal Bank of Canada had security on virtually all of the assets of J.C. International for a debt which far exceeded the value of those assets. Mr. L.C. Cole, President of J.C. International had also stated in an affidavit sworn on July 22nd, 1986, that the company owed the sum of $\$ 24$ million, more or less, to the Royal Bank and that this debt was secured by both debenture and Bank $A c t^{23}$ security covering substantially all the assets of the company. In addition, he stated that the company owed approximately $\$ 2.5$ million to its preferred and ordinary creditors, was insolvent and possessed assets of a value less than its debts.

The respondent Clarkson Gordon submitted that the relief sought should be denied since there were triable issues to be determined, in particular the question of insolvency. It argued that the company may not have been insolvent since:

(i) some of its debts had been paid with additional funds advanced by the Royal Bank,

(ii) the plaintiffs were estopped in their cause by virtue of representations made by officers of TriStar to the effect that no steps would be taken to remove J.C. International as operator,

(iii) in a separate joint application of Tri-Star and Copetrex there were seven parties with working interests, with no guarantee that Copetrex or Tri-Star would be named to represent such working interests as operator, and

(iv) the bank, who had appointed Clarkson Gordon as its agent to take custody of the assets of J.C. International pursuant to its security, would refuse to continue to fund the proposal and bankruptcy would follow.

Through various transactions, J.C. International had obtained a 55\% working interest in the relevant lands prior to the proposal being filed. Copetrex and Tri-Star

17. Tri-Star Resources Ldd. v. J.C. Int. Petroleum Ltd. (1986), 48 Alta. L.R. (2d) 355 (Q.B.) [hereinafter Tri-Star].

18. Norcen Energy Resources Limited v. Oakwood Petroleums Lid. (1988), 63 Alta. L.R. (2d) 361 (Q.B.) [hereinafter Oakwood].

19. The Rimoil Corporation v. Hexagon Gas Ldd., Dynamar Energy Limited and Brannigan Resources Canada Ld., May S, 1989 (unreported) [hereinafter Rimoil].

20. Supra, note 17.

21. Supra, note 4.

22. See Paragraphs 206(a) and (b) of the 1981 Procedure.

23. Bank Act, R.S.C. 1985 , c. B-1. 
had both notified J.C. International in accordance with their separate respective operating agreements, each incorporating the 1981 Procedure, that pursuant to Paragraph 206(b) thereof, each was the new operator thereunder and that pursuant to Clause 207 thereof, all well data and other facilities, equipment and documents were to be delivered to them.

On the first argument, Mr. Chief Justice Moore held that: ${ }^{24}$

. . . there is no issue to be tried on the question of "insolvency". The company, by Mr. Cole's own admission as stated in his Affidavit of 22 nd July, was unable to meet its obligations and was insolvent. Black's Law Dictionary defines "insolvency" as an "inability to pay one's debts". Surely when the President of the company under oath states that the company is unable to pay its debts there can be no further argument on the question.

On the question of estoppel, he further concluded that the equitable remedy of estoppel could not be relied upon in view of the specific wording of Clause 202 which was for the protection of the non-operators having regard to the fact that the company was already in a state of insolvency. Moreover, he stated that the mandatory nature of the words "shall be replaced immediately" dictated that J.C. International should be replaced by the party having the next greatest interest in accordance with the provisions of Paragraphs 206(b) and (d) of the 1981 Procedure. The court then granted the separate applications, declaring Tri-Star and Copetrex as the new operators under the two operating agreements, and further directed that the respondents comply with the provisions of Clause 207 of the 1981 Procedure which governs the transfer of property on a change of operator.

In the Oakwood case ${ }^{25}$ the first question requiring resolution was whether or not Oakwood was insolvent within the meaning of the 1981 Procedure. Mr. Justice Forsyth applied the test set forth in the Tri-Star case ${ }^{26}$ and concluded that the affidavit of an executive vice-president of Oakwood, which contained numerous admissions that Oakwood was unable to pay its debts, was sufficient to establish the fact of insolvency.

The basic issue under consideration in the Oakwood case ${ }^{27}$ was whether or not Oakwood should be afforded the protection of the Companies' Creditors Arrangement $A{ }^{2{ }^{28}}$ as being a debtor company within the meaning of the $C C A A{ }^{29}$ Mr. Justice Forsyth expressed the view that it would be difficult to argue on one day that you are insolvent and that you deserve the protection of the $C C A A^{30}$ for one purpose and then argue on another day, for another purpose, that you are not insolvent within the meaning of the relevant operating procedure. The Royal Bank had argued that Oakwood was "commercially solvent" even though it may have been "legally insolvent", apparently on the basis that it was meeting day to day obligations though not long-term obligations. The Court rejected this argument and concluded that insolvency was to be given its normal meaning under the agreement and could not be interpreted as being restricted only to the meeting of day to day expenses and making payments to the other joint-operators. The court also

24. Supra, note 17 at 360 .

25. Supra, note 18.

26. Supra, note 17.

27. Supra, note 18.

28. Companies' Creditors Arrangement Act, R.S.C. 1985, c. C-36 [hereinafter CCAA].

29. Ibid.

30. Ibid. 
noted that under Clause 306 of the 1981 Procedure one of the duties of the operator is to pay all trade debts, and that under Clause 605 there is an obligation upon the operator to distribute income to those entitled to it. Finally, he concluded that "by the bringing of its [CCAA $\left.A^{31}\right]$ application, Oakwood has declared itself insolvent and thus Clause 202 of its operating agreement came into play"..$^{32}$

The second issue, which may be of more concern for non-operators, was whether or not the fact of insolvency created an automatic ejection of Oakwood from its operatorship or whether some further action in that regard was required by Norcen. Notwithstanding the provisions of Paragraph 206(d) which called for immediate replacement of the operator, the court concluded that its effect was simply that no waiting or notice period was required. This was also considered in the context of Paragraph 206(a), which provides that if there are only two joint-operators, the other joint-operator would have the right to become the operator, a consideration found to be most important in these circumstances. In his reasons for judgement, Mr. Justice Forsyth stated: ${ }^{33}$

It appears to be worded in the future tense suggesting that at some point following insolvency another party may become the operator if appropriate measures are taken. There is some positive election required on Norcen's part indicating that it wants to exercise its right to become the operator.

If faced with a situation where the facts would appear to support the nonoperators' position that they have the right to remove an operator, the operator could choose to seek the protection of the $C C A A{ }^{34}$ This could be a risky step for an operator to take since in order to do so, insolvency is necessarily admitted and, upon termination of any stay of proceedings which is granted (as in respect of a bankruptcy), the non-operators would appear to win the day. Norcen raised this issue in its arguments before the court and suggested that if the stay were allowed, its right to become operator could be adversely affected, since during that period of time Oakwood might cure its insolvency. The Court did not decide whether the ability of Oakwood to cure its insolvency did adversely affect Norcen, although Mr. Justice Forsyth noted that he was mindful of this concern and its implications for Norcen.

It seems arguable on one hand that any curing of the insolvency during a stay imposed pursuant to $C C A A^{35}$ should not adversely affect the ability of the nonoperators to have the operator removed, since it is the fact of insolvency or an act of bankruptcy or insolvency at the time that it occurs which is important and relevant for purposes of the 1981 Procedure. If the non-operators have acted expeditiously in initiating proceedings to exercise their rights and have the insolvent operator removed, and such proceedings are affected by a stay, the non-operators should not have their rights prejudiced on a permanent basis. To allow the insolvency to be cured, thereby defeating the rights of the non-operators to have the operator replaced, would suggest a form of relief against forfeiture of a right which may be inappropriate in such circumstances.

From the point of view of the insolvent operator and its creditors, it may be argued that the precise intention of the $C C A A^{36}$ is to allow the insolvent party

31. Bbid.

32. Supra, note 18 at 370 .

33. Supra, note 18 at 371.

34. Supra, note 28.

35. lbid.

36. lbid. 
interim relief to permit it to put its affairs in order. It may also be argued that there is a greater intrinsic value if a sale or other disposition could be made of the insolvent operator as a going concern, which would have greater benefits for all concerned, including non-operators which may be adversely affected by a bankruptcy. If the insolvent operator cures its insolvency, it could be argued that it should be able to defeat any challenge to its operatorship that might be made on that basis. However, it may be suggested that this argument does not address a fundamental issue for non-operators, namely that operatorship is at least not intended to be financially based, since it is not intended that operatorship serve as a centre of profit. However, it is also clear that an operator does receive a benefit through the use of the non-operator's funds while in its possession, and may well benefit financially by serving as operator.

The appropriate balancing of interests in the type of situations that may arise would depend on a number of factors, such as the presence of any specific and unique knowledge that the operator's employees might have with respect to operation of the relevant lands which could be lost if they were terminated, the current status of the lands as an exploration, development or mature operation, the general capabilities of the operator as an operator, the abilities of one or more of the nonoperators to assume operatorship should they wish to do so and the potential financial recovery for all concerned if some form of reorganization of the operator is achieved. It would seem that each situation must be examined on the basis of its own special merits, and generalizations may be inappropriate.

Mr. Justice Forsyth did grant the stay in the Oakwood case, ${ }^{37}$ presumably accepting Oakwood's evidence that if Oakwood were removed as operator this would be fatal to attempts to restructure the company. Since the Court found that Section 11 of the $C C A A^{38}$ was to be given a wide interpretation, it was concluded that the stay could extend to and interfere with contractual obligations, whether or not the parties being interfered with were creditors in fact or in effect. It is perhaps unfortunate that this case was not appealed to confirm whether or not this interpretation settles the issue. Whether or not the non-operators could successfully continue with proceedings for removal of an operator which has, in one form or another, cured its insolvency during a stay that was granted, is an open question, since it is understood Norcen did not pursue this matter after the stay was lifted and apparently accepted the successor to Oakwood as operator. This decision would appear now to be the law applicable in Alberta, although it may be subject to further refinement by the courts, since this case could be found to be confined in application to its own particular facts.

One issue that is not specifically dealt with in Clause 202 of the 1981 Procedure are the implications attendant on a "receivership" of the operator. As a receivership order is a natural consequence of a successful petition for bankruptcy, there should be no issue as to whether or not such a party is bankrupt or insolvent since the order issued is predicated on a determination of that very issue. However, it is possible for a private receivership to take place pursuant to a debt instrument such as a debenture, which does not necessarily include a court order to this effect, although it is understood that the usual practice is to obtain a confirming court order. The standard debenture, whether or not in the nature of a demand, will provide that

37. Supra, note 18.

38. Supra, note 28 . 
the security evidenced by the instrument shall become enforceable upon the event of a default, such as the failure to make payments to the secured party when due. It should be noted that such an event may not, in and of itself, be sufficient to prove that the operator is insolvent, or that it has committed an act of bankruptcy or insolvency. Failing to make payments when due under a debt obligation secured by a debenture would arguably constitute an act of bankruptcy or insolvency. However, a non-operator advancing such a claim will very likely be invited to prove this to be the case. Short of court action, it is highly unlikely that the non-operator will have sufficient information available to it to prove its case and effect a change of operator. Further, it is possible, although unlikely, that the operator will survive the receivership and regain control of its own destiny.

For the 1988 Procedure a proposed amendment to Paragraph 202(a) provides for immediate replacement of the operator if it is either placed in receivership or makes a proposal to creditors pursuant to section 33 of the Bankruptcy Act. ${ }^{39}$ However, this amendment may not adequately address all potential problems. It may be appropriate for the 1988 Procedure to consider the implications of an operator making an application under the $C C A A^{40}$ and whether this should entitle the non-operators to effect a removal of the operator, although the courts may not enforce such a provision, given the broad interpretation afforded to section 11 of the $C C A A{ }^{41}$ If the CAPL is to address such matters, it may be appropriate to provide for elections by the non-operators, rather than to provide for automatic ejectment of the operator, to permit the affected parties to review the matter and the implications of their actions.

It is sometimes difficult to understand the preoccupation with keeping the operator in that position in the circumstances outlined above. One could suggest that it is usually easier to sell properties of the bankrupt if operatorship is maintained and can be transferred to the purchaser. However, it may be noted that under the 1981 Procedure, operatorship does not automatically follow in a disposition of an interest subject to an operating agreement, although that usually will be the case if the largest participating interest is involved in such a disposition. On the negative side, a receiver may only be concerned with the short term goal rather than any long term strategy or investment potential and thus development may come to a standstill in a receivership situation. From the point of view of costs, an operator faced with bankruptcy or receivership may also be able to reduce its overhead costs significantly if it did give up operatorship, through reduction in operating staff and the like. A lean organization may be more attractive to some buyers who do not want the added burden of staff who may well turn out to be redundant.

In Sub-paragraph 202(a)(ii) of the 1981 Procedure, it is stated that an act by the operator of assigning or purporting or attempting to assign its general powers and responsibility of supervision and management constitutes grounds for removal. It appears that this provision is intended to preclude the operator from entering into agreements for contract operation of the joint lands which would effectively remove the operator for all intents and purposes from the management of such joint lands. It may also address a cost concern, since the operator may attempt to charge the

39. Supra, note 4.

40. Supra, note 28.

41. Ibid. 
third party costs incurred to the joint account, and such costs would likely be greater than the operator would otherwise be entitled to charge under the accounting procedure.

It is common practice for operators to enter into well operating contracts and similar agreements with other operators for convenience or other reasons in areas where such other operators have significant operations. If there are no imminent plans for development of the joint lands, day to day supervision and management may well be appropriately undertaken by a contract operator rather than by the operator itself. Entitlement to replace the operator in such circumstances may not have been the intended result of entering into such an arrangement. If the relevant operating procedure applied to one section of land upon which a sole gas well was located, the entering into of a contract well operating agreement presumably could be sufficient to place the operator in violation of this provision and entitle the non-operators to take the position that the operator is to be replaced. However, it may be noted that such contract well operating agreements usually have termination clauses of short duration so the situation could be easily resolved by the operator. Further, the operator could argue that the ultimate responsibility has not been surrendered, which would likely be the case.

In the Rimoil case, ${ }^{42}$ the plaintiff Rimoil claimed a right to be appointed operator in the place and stead of the existing operator on the basis that it had breached the provisions of Paragraph 202(b) of the 1974 Procedure by assigning its general powers of supervision and management as operator. Although it is difficult to ascertain the precise (and all relevant) facts from the reasons for judgment, it appears that Hexagon, a subsidiary of Dynamar, was the named operator under a number of operating agreements. In May of 1985 it purported to assign operatorship to Dynamar. By May of 1988 Dynamar was insolvent. The Royal Bank had debenture security against the assets of Dynamar and a receiver-manager was appointed. After the receiver-manager of Dynamar was unable after several attempts to sell its assets for what was considered by the Royal Bank to be an adequate price, such assets were, with the approval of the Court, conveyed by the receiver to Brannigan, a wholly-owned subsidiary of the Royal Bank. On January 18, 1989 Hexagon purported to assign its operatorship to Brannigan. On February 14, 1989 Brannigan, Hexagon and the receiver-manager for Dynamar gave written notice to the working interest owners under the various operating agreements of a meeting intended for proper novation of all appropriate working interest owners into their operating agreements, and to appoint or confirm appointment of operator. At the meeting held on March 2, 1989, the requisite majority vote was only obtained in respect of one operating agreement. Nonetheless, it is apparent that Brannigan continued in the role of operator for all of the operating agreements in question.

The Court accepted the fact that breaches of Paragraph 202(b) had occurred, but did not accept that Rimoil had the right to become operator without a vote, particularly in view of the interim vote taken at the March 2 meeting, at which Rimoil had voted. The Court concluded that a meeting must be called to effect a change of operator pursuant to Paragraph 206(a). If the requisite majority cannot be obtained, then pursuant to Paragraph 206(b), the joint-operator with the greatest participating interest will act as operator pro-tem. In this situation the Court found that Rimoil would have to prove its entitlement under Paragraph 206(b) in respect

42. Supra, note 19. 
of those operating agreements where the requisite majority had not been obtained, but that in any event Brannigan had been validly appointed under the one operating agreement.

Paragraph 202(b) of the 1981 Procedure provides two additional situations in which the operator can be removed, although it is not a requirement that this removal occur immediately. The first is where the operator ceases to hold or represent at least $10 \%$ of the participating interests. This provision would seem to be the automatic result of a disposition by the operator of all of its interest in and to the joint lands. However, the operator and the purchasing party may provide in their purchase and sale agreement that the operator will continue to represent the interest pending the execution and delivery by all parties of an assignment and novation agreement, in which the transfer to the purchaser of the interest in the lands and the relevant operating agreement is recognized by all affected parties. It is doubtful if the $10 \%$ rule would become operative in such circumstances. This is obviously an undesirable situation from the point of view of the non-operator, since an operator ceasing to have a beneficial interest in the joint lands will clearly not have the interests of the non-operators at heart. The most desirable result in the circumstances of a disposition by an operator of its interests will, of course, depend on the particular situation, making it difficult to draft appropriate provisions of general application.

If there is an existing non-operator having a substantial interest in the relevant lands, it may well be desirable for that party to assume operatorship. For a variety of reasons the other non-operators may not want the purchasing party to assume conduct of operations and may refuse to execute an assignment and novation agreement that attempts to have this effect or otherwise confirm the purchaser as the new operator. In such circumstances the non-operators would be well within their rights since operatorship does not automatically transfer to the purchaser on an operator's disposition of its interest in the relevant lands and operating agreement. However, if the purchaser will be assuming a significant participating interest which exceeds that of the other non-operators and is an experienced and reliable operator with a good track record, it may be desirable for such a party to assume operations immediately for the benefit of all of the joint-operators.

Perhaps appropriately, the 1981 Procedure does not address all the various situations that can develop in a disposition, and it is often possible for stalemates to occur. In the event of a permitted disposition, it is in the interests of all concerned that a suitable assignment and novation agreement be entered into. Such an agreement does not and perhaps should not release the operator from obligations it may have assumed while it was the operator. However, it would be useful to provide that a vote be held for the appointment of a new operator or confirmation of the purchaser as operator within a reasonable period of time after closing of the disposition, whether or not the operator is said to continue to represent the interest being disposed of. It is reasonable for the non-operators to have the opportunity to address the question of operatorship upon a disposition, or perhaps even on a periodic basis, such as every few years, particularly when it is so difficult to remove an operator once appointed.

The proposed changes for the 1988 Procedure reflect a direct approach and simply state that the operator may be replaced by the affirmative vote of two or more joint-operators representing a majority of the participating interest. This suggested 
change will resolve many multiple ownership situations, but not the situation where the existing operator holds $50 \%$ or more of the relevant participating interest. There are also situations where there are only two joint-operators, each holding an undivided $50 \%$ participating interest, with the non-operator potentially being more qualified than the operator at the relevant time to conduct operations for the joint account, but without apparent ability to effect a change other than pursuant to a challenge of operator.

The second additional provision which may result in the removal of the operator is described in Sub-paragraph 202(b)(ii) of the 1981 Procedure. This is where the operator defaults in its duties or obligations and does not commence to rectify the default within $\mathbf{3 0}$ days after written notice from a majority in interest of the joint-operators (excluding the operator) specifying the default and requiring the operator to remedy it. The primary duties and obligations of the operator are as set forth in Article III, which appears to set the reference point for any challenge that might be made on this basis. If a non-operator can find a described obligation that is not being satisfied by the operator, it could utilize such a provision to attempt to effect a change in operator. However, it is clear that the operator could also commence to remedy the default within the specified time and thus defeat the challenge. It may also be noted that the provision does not require the operator, after commencing to remedy the default, to act diligently or even continue with such remedy until completed. Although this could be considered an implied term, it would appear to be a defect requiring appropriate rectification.

\section{Challenge of Operator}

Clause 203, entitled "Challenge of Operator", is one of the more controversial and for the most part ineffective provisions through which a non-operator might gain control of operations. A non-operator may issue a "challenge notice" to all joint-operators to the effect "that it is ready, able and willing to conduct operations for the joint account on more favorable terms and conditions" ${ }^{43}$ It is a condition precedent to the right to issue a challenge notice that the existing operator has been in place for at least two years. ${ }^{44}$ If that requirement is satisfied, the challenge notice may then be issued. The issue that arises in this context is what constitutes "more favorable terms and conditions", since no reference point is provided. To the writer's knowledge this provision has not been specifically tested in the courts.

However, the Appellate Division of the Supreme Court of Alberta in the Permo Gas case ${ }^{45}$ considered the meaning of the words "upon terms more favorable" in the context of a favoured nations clause in a gas purchase contract. The Court focused on the word "terms" as requiring interpretation in the context of this case, and stated: ${ }^{46}$

... if it means a difference in one item of several making up the computation of the sale-price, the appellant is entitled to succeed. If, however, "terms"' has a broader meaning, requiring that the con-

43. Clause 203, 1981 Procedure.

44. Bbid.

45. Permo Gas \& Oil Limited v. Pacific Petroleums Lid. (1963), 43 W.W.R. 231 (Alta. Sup. Ct. App. Div.) [hereinafter Permo Gas].

46. Ibid. at 235 and 236. 
tract as a whole, or at least several clauses of it, must be looked at to determine if its terms are more favourable, then the interpretation which the appellant asks to put upon these words must be rejected.

"Terms" is expressed in the plural. It does not follow that a single term may not be sufficient to bring the favoured nations clause into operation. For instance, if all terms of two agreements except one are the same, one more favourable term would make the "terms" of that agreement "more favourable".

It may be argued that this is precisely the question that arises in reference to Clause 203 of the 1981 Procedure. All terms of the agreement under which the challenging non-operator would function will be similar, except for those it asserts will be performed on a more favorable basis. There are no express restrictions on the terms founding a non-operator's challenge. Although the normal challenge would be financially based, a challenge may be predicated on operational viability, such that the requirements of all of the parties are satisfied.

There is no specific guidance as to what magnitude of change will be sufficient to satisfy the "more favorable" requirement, but it is submitted that a court would likely apply a reasonable test requiring the effect to be more than nominal, and if financially based, to at least represent a material economic benefit for the other joint-operators. A challenge based on improved operations may be more difficult to establish, but is no less important from a non-operator's perspective.

If a non-operator does decide that it wishes to challenge the operator, it should first carefully weigh the potentially adverse consequences of doing so, since whatever the result, it may be difficult for the parties to continue to carry on joint operations. The negative feelings generated by such actions may also carry over into other operations in which the operator and non-operator are jointly involved. Thus, if a non-operator elects to issue a challenge notice, it should at least be reasonably certain that it has a good chance of success on the merits and be prepared to accept the possible negative consequences.

If a challenge notice is issued, the operator has a positive obligation to respond within 60 days and to advise the non-operator either that it is prepared to operate on the terms and conditions set out in the notice and, if so, must forthwith proceed to do so, or that it is unable or unwilling to operate on such terms and that it will resign as operator effective not later than 90 days following the aforementioned 60-day notice period..$^{47}$ If the operator fails to respond to the notice within the 60 day notice period, he shall be deemed to have elected to resign. ${ }^{48}$

Two observations can be made about the potential implications of the operatorship challenge. First, the operator may accept the terms and conditions, and if he does he is entitled to continue as operator. ${ }^{49}$ Secondly, if he elects not to do so, and the challenge notice has been given near the beginning of a month, a period of time close to 180 days may pass before the change of operatorship will be effected, ${ }^{50}$ and potentially longer if there is resistance by the operator. In neither circumstance will the non-operator likely have met its immediate objective of assuming conduct of operations in a timely manner. It may also be noted that it is very likely that the charges to which the operator is entitled under the accounting

47. Clause 203, 1981 Procedure.

48. Ibid.

49. Ibid.

50. If the notice were given on the second day of a 30 day month, the effect of paragraph 206(d) would be to bring the total time to 178 days before the change is to be effected. 
procedure may be of far less benefit than the utilization of cash it holds from time to time that properly belongs to the non-operators, such that it may well elect to operate on the proposed terms to retain any advantage it may have been enjoying in this latter regard.

Therefore, if after an assessment of the situation, it may reasonably be expected that an operatorship challenge notice will not be successful, the non-operator may be better served by looking to the independent operations provisions of the 1981 Procedure ${ }^{51}$ discussed later in this paper as a means of effecting an increased level of activity in respect of the joint lands.

\section{B. COSTS AND EXPENSES}

\section{Advances, Cash Calls and Payments}

Article V of the 1981 Procedure provides that the operator is to pay all costs and expenses of the operation and then to recover from the other participants their proportionate shares of these costs and expenses. One of the most common areas of dispute between operators and non-operators deals with issues arising from the costs and expenses incurred for the joint account of the parties. Clause 501 provides that the attached accounting procedure ${ }^{52}$ is to be the basis for all charges and credits to the joint account. This Clause remains unchanged from the 1974 Procedure and no change is at present contemplated for the 1988 Procedure.

Clause 502 of the 1981 Procedure provides that the operator is initially to advance and pay all costs and expenses of the operation and is to then charge each nonoperator its proportionate share of such costs and expenses. The 1974 Procedure provided each non-operator with 15 days to make such payments after receipt of the operator's statement thereof and the 1981 Procedure increases this time to 30 days. No change is proposed in the 1988 Procedure. Clause 502 further provides that any amounts unpaid by joint-operators may bear interest at the operator's option. The Alberta Court of Appeal held in the Renaissance case ${ }^{53}$ that in order for an operator to be entitled to interest on amounts unpaid by non-operators, the operator must notify the non-operator of its intention to elect to charge interest on such unpaid amounts, as provided by Clause 502 . That is to say, the interest provisions do not automatically take effect and positive steps are required to be taken by the operator for them to do so.

Clause 503 provides the operator with an option whereby it can require, through cash calls, the advance payment by the non-operators of their respective share of costs and expenses. Essentially, Clause 503 provides that the operator may, at its option, require each of the other non-operators to advance their proportionate share of costs and expenses prior to their actually being incurred by the operator. The 1974 Procedure provided that such advance payments were to be made by the non-operator within 15 days of receipt of the notice or by the first day of the month to which the notice applied, whichever was later. The 1981 Procedure extends the

51. Article X.

52. Usually now the 1983 Petroleum Accountants Society of Westem Canada ("PASWC") Accounting Procedure or the 1988 Petroleum Accountants Society of Canada ("PASC') Accounting Procedure.

53. Renaissance Resources Ltd v. Metalore Resources Ltd., [1984] 4 W.W.R. 430 (Q.B.); (1985), 38 Alta. L.R. (2d) 133 (C.A.) [hereinafter Renaissance]. 
period for payment until the 15th day of the month to which the notice applies. This time period remains unchanged in the 1988 Procedure. Provisions permitting cash calls to be made are of particular concern to a non-operator where the financial stability of the operator is in question.

The 1974 Procedure required adjustments between advances made by nonoperators and the actual costs incurred to be made at the end of each month. The 1981 Procedure requires by Clause 503 that such unused amounts be refunded to the non-operator in a prompt and timely manner, but in any event prior to the end of the month following the month to which the advance applied. If the operator fails to make such a refund, the non-operator is entitled to interest on the unpaid amount, at the non-operator's option. The non-operator would have to give notice to the operator of its intention to elect to charge interest under Clause 503, assuming that the principle set forth in the Renaissance case ${ }^{54}$ applies to this situation, which seems likely.

Extensive changes have been proposed to Clause 503 in the 1988 Procedure. Provision is to be made for a "cash call" whereby the operator may elect to require the joint-operators to advance their proportionate share of all costs and expenses to be incurred pursuant to an approved AFE. There is provision for such advances to be made in the form of an irrevocable standby letter of credit established by a chartered bank in Canada in favour of the operator. The operator then draws on the standby letter of credit in the same manner and at the same time as provided with respect to cash calls. The risks for non-operators are obvious, but the provision is clearly intended to deal with problems which operators encounter in circumstances where non-operators elect to participate but do not provide the requisite funding when required to do so. If these provisions are implemented, the non-operators will have an increased level of concern regarding an operator in financial difficulty who could call on the letter of credit, whether or not entitled to do so at the relevant time.

Provisions by which an operator may make a cash call under the proposed 1988 Procedure are essentially the same as provided for in Clause 503 of the 1981 Procedure. The operator must submit to the non-operator an itemized written estimate of the costs and expenses to be incurred under the AFE together with a request for the non-operator's payment of its proportionate share of these costs relating to the calendar month in question. This estimate may be submitted not earlier than 30 days prior to the first day of the calendar month in question. The non-operator then has 15 days from receipt of this estimate or until the 15th day of the calendar month in question to pay its cash call.

In addition, the proposed amendments for the 1988 Procedure provide that the non-operator can require by notice in writing to the operator that the operator use a trust account for the collection and disbursement of funds paid pursuant to the cash call. The operator is then required to deposit such funds into a trust account and to pay all costs and expenses incurred pursuant to the AFE for which the cash call was submitted from the funds deposited in the trust account. Clause 503 then provides that if the costs and expenses incurred are greater than the amounts deposited in the trust account, the operator shall submit a further cash call or invoice to the non-operator for its share of such additional costs and expenses. If the costs and expenses incurred are less than the funds deposited in the trust account pursuant

54. Bbid. 
to the cash call, the operator is required to refund to each joint-operator paying such cash call its share of the funds still held in the trust account, either when all costs and expenses have been paid or one year from the date of commencement of the operation contemplated by the AFE, whichever is earlier. The 1988 Procedure also provides that unpaid cash calls may bear interest, at the operator's option. Again, on the authority of the principle applied in the Renaissance case,,$^{55}$ notice of the election to charge interest must be given if the entitlement to interest is to arise.

The 1988 Procedure as proposed also provides that where a non-operator fails to pay its cash call within the time specified, the non-operator shall be denied any further information regarding the operation, and the operator may, at its option and on 10 days notice to the joint-operator, assume the defaulting joint-operator's share of costs and expenses related to the operation. This provision apparently does not afford the remaining non-operators the ability to "step up" their interests until payout of the well. A non-operator who fails to meet a cash call is deemed to be a non-participating party in the operation and to be subject to all of the applicable provisions of Article X. If the operator chooses to invoke this option then it foregoes any recourse under Clause 506 to recover unpaid amounts from the remaining joint-operators.

The 1988 Procedure further proposes in Clause 503 that the provisions of this clause shall in no way limit or restrict the rights of the operator as contained therein or otherwise at law or in equity, to bring an action for payment of any outstanding amounts owed to it by a non-operator. Finally, the draft 1988 Procedure follows the 1981 Procedure in providing that amounts advanced by a non-operator and then not required by the operator shall be refunded to the non-operator in a prompt and timely manner, but in any event prior to the end of the calendar month following the month to which the advance applied. If such refunds are not made by the operator, the unpaid amounts may bear interest, at the option of the non-operator, which as previously noted would require a positive act by such non-operator to be effective.

Clause 504 provides that at the request of the joint-operator, the operator shall furnish a written forecast outlining all operations which it proposes to carry out on the joint lands for the joint account during the forecast period, together with the estimated cost thereof. This Clause specifies that it is understood that such forecasts are for informational purposes only and shall not bind any of the parties. Clause 504 remains unchanged from the 1974 Procedure and no changes are yet proposed for the 1988 Procedure.

\section{Default and Remedies}

Clause 505 of the 1981 Procedure, which makes provision for the operator to have a lien on the interests of the non-operators as an additional protection in the event that a non-operator fails to pay its proportionate share of costs and expenses, remains unchanged from the 1974 Procedure. This Clause provides that the operator has a lien on the interest of each non-operator in the joint lands and in the production, wells and equipment therefrom and thereon to secure payment of each joint-operator's proportionate share of the costs and expenses of operations carried on by the operator for the joint account. If a non-operator fails to pay or advance 
any of the costs required and his default continues for 30 days after the operator has served notice on the joint-operator specifying this default and requiring the same to be remedied, the operator has a number of options.

First, the operator may withhold from the non-operator any further information and privileges with respect to the operation. Secondly, the operator may treat the default as having immediately and automatically assigned to the operator the proceeds of the sale of the non-operator's share of the petroleum substances. After making such an election, the operator may require the purchaser of the jointoperator's share of the petroleum substances to make payment therefor directly to the operator while the default continues. Thirdly, the operator may enforce the lien by taking possession of all or any part of the defaulting non-operator's interest in the joint lands or in all or any part of the production therefrom and equipment thereon. The operator may then sell or dispose of any interest, production or equipment of which it has taken possession either in whole or in part or in separate parcels at public auction, or by private tender on whatever terms it shall arrange, having first given notice to the defaulting non-operator of the time and place of the sale. The proceeds of such a sale are to be applied first in payment of any costs which the defaulting non-operator would pay with the balance remaining, if any, to be paid to the defaulting non-operator after deducting reasonable costs of the sale. This Clause specifies that any such sale shall be a perpetual bar both at law and in equity against the defaulting joint-operator and its assigns and against all other persons claiming the property or any part or parcel thereof sold as provided.

There are many practical problems associated with implementation of the remedies afforded to the operator as outlined above. From the point of view of the non-operator, these provisions could be disastrous if the operator were successful in implementing them, having particular regard to the assignment of proceeds and the enforcement of the lien through the sale of the non-operator's interest. In the former case, many buyers will not respond to a request for payment without the contracting parties' consent. If it is not forthcoming, they will usually hold back the funds or pay them into court. In the latter case, the interest to be sold could already be pledged as security to a lender and the actions by the operator could trigger a default under the security documents applicable to the non-operator's interest. It would appear that any operator exercising this option would be faced with a situation where the security would remain applicable to the lands and interests making them of limited value to any prospective purchaser. If the operator were to take the position that it was entitled to assume the interest in the lands for its own account, it would have obligations of a fiduciary nature and the question of valuation would be a problem. For practical reasons, it is unlikely that the remedies indicated as available to the operator would be enforceable against a non-operator, short of court action by the operator. It may also be noted from the point of view of the nonoperator, that under section 10 of the Judicature Act ${ }^{36}$ the non-operator could apply for relief from forfeiture which may well be granted should the non-operator be able to bring its default into good standing.

The 1988 Procedure follows the default and remedy provisions of the 1981 Procedure with only minor changes. Where the 1981 Procedure provides the operator with the three options listed above when a default by a non-operator continues for 30 days after the operator has served notice of the default, the draft 1988 Procedure 
provides that the operator may invoke these options where a non-operator fails to make payment within the time periods required in Clause 503. The draft 1988 Procedure further provides that the non-operator who is acting in the capacity of operator for the joint account has the same rights and obligations as those granted to the operator under Article $\mathrm{V}$, which is of considerable interest to non-operators who may become operators through the application of the independent operating provisions.

Clause 506 makes provision for the operator to recover the unpaid portion of a non-operator's share of costs and expenses from the other non-operators if such costs and expenses are not paid within three months following the date the payment was due. The operator is to bill the other non-operators for their proportionate share of the unpaid amount, excluding any interest thereon. Each non-operator who so contributes to the unpaid amounts shall be proportionately subrogated to the operator's rights pursuant to Clause 505 and to the interest thereafter payable under Clauses 502 and 503 on the recovered portion of its contribution. Clause 506 remains essentially unchanged from the 1974 Procedure and no changes are presently proposed for the 1988 Procedure.

\section{Trust Obligations and Commingling of Funds}

Clause 507 of the 1981 Procedure provides that the operator may co-mingle its own funds with the funds which it receives from or on behalf of the joint-operators. This provision has been the subject of significant debate and judicial scrutiny with regard to the question of whether or not the operator is a trustee for the non-operators in regard to funds received from them or on their behalf. The Alberta Court of Appeal held in the Sorrel case ${ }^{57}$ that a trust was created despite the absence of express trust language. The operator's right to co-mingle funds under Clause 507 was deemed simply to be an administrative aid to the smooth implementation of the operating procedure and not a negation of the trust relationship between the operator and the non-operator in regard to these funds.

In the Sorrel case, ${ }^{58}$ there was no apparent distinction raised between sums that a non-operator advances or pays to the operator to fund operations and funds of an operator that are initially received by the operator from third parties for the sale of production or otherwise for subsequent distribution to the non-operators. The inferred thrust of the Sorrel case $\mathrm{e}^{59}$ is that it was not the apparent intention of the non-operators to place their funds at risk to the creditors of the operator. With respect to cash calls and the like, the funds are paid for a specific purpose, namely the operation in question.

There is a potential distinction between funds advanced to the operator and funds received from third parties, such as from the sale of production, that turns on the intention of the parties as inferred from the agreement, and which merits consideration. This latter situation will usually arise where the non-operators do not take their production in kind such that the operator must invoke the provisions of Clause 602 of the 1981 Procedure and sell such production for the account of the nonoperator. Otherwise, such sales would be made outside of the operating procedure

57. Bank of Nova Scotia v. Societe General (Canada) (1988), 58 Alta. L.R. (2d) 193 (C.A.) (hereinafter Sorrel].

58. Bbid.

59. Ibid. 
and therefore would not be subject to its provisions. Such circumstances would appear to be more akin to that of a debtor-creditor relationship than a fiduciary relationship. The funds come into the possession of the operator in effect through a default by the non-operator in meeting its obligations under Clause 601 of the 1981 Procedure. There is no clear intention not to place the funds at risk or to use the same for a specific purpose. The operator in such circumstances merely acts as a collector of revenue, although it obviously would have trust obligations to the extent that it could not use such funds for its own purposes. Notwithstanding this potential distinction, it would appear that, based on the Sorrel case, ${ }^{60}$ the two situations are essentially indistinguishable in terms of the trust that is created.

What is unclear at this point is whether this principle as applied in respect to the 1981 Procedure would follow through to supplementary agreements and arrangements which the operator entered into for the sale of production for and on behalf of itself and the non-operators independent of the 1981 Procedure. Such agreements would arguably have nothing to do with the conclusions reached in respect of the 1981 Procedure and would have to be interpreted on their own merits. Non-operators would be wise to ensure that such agreements include appropriate trust language in an attempt to avoid having such funds placed at risk of loss in circumstances over which they have no control.

Notwithstanding the arguments applicable to the Sorrel decision ${ }^{61}$ and the conclusions reached therein, there is still a practical problem in circumstances where the operator has gone into bankruptcy or receivership, and all that remains is an account where funds have been co-mingled. From the point of view of the non-operators, any rights they may have directly against the operator as "trustee" for breach of trust will be of little value since the trustee in these circumstances is likely insolvent and without any property of its own in excess of that owed to or encumbered by its secured and other creditors. Therefore, the non-operators may be forced to look to a pool of co-mingled funds remaining, if any, to recover funds owed to them. The problem is then to ascertain which funds properly belong to the operator and are thus subject to attachment by any security which it has granted, and which funds properly belong to the non-operators as beneficiaries of the "trust". Where the funds are in the hands of a third party, such as a bank, the equitable remedy of tracing may be available to the non-operators to trace their funds into the mixed account. If the non-operator cannot show that his monies were placed in the account, he may be without a remedy. If he can show that the funds were received into a particular account, whether mixed or not, he should be able to establish priority on the basis of the trust argreement and trace such funds. A "presumption of regularity" has application to the operator's actions, such that the operator as trustee is presumed to have met its trust obligations, in the absence of evidence to the contrary. If trust monies have been misappropriated the operator will be in breach of a trust obligation to the cestui que trust or beneficiary.

Another potential difficulty that arises in this regard is where the non-operator can show that the account includes its funds, but where the account is now insufficient to pay all non-operators under separate agreements. D.W.M. Waters has suggested $^{62}$ that it may well be the law in Canada that the first funds to be placed

60. Ibid.

61. Bbid.

62. D.W.M. Waters, The Law of Trusts in Canada, 2nd ed. (Toronto: Carswell, 1984). 
in trust are the first to be deemed to have been withdrawn, such that a non-operator whose funds are placed in the account later may in fact take priority over one whose funds are placed in the account earlier. This is in effect an application of the rule in Clayton's Case. ${ }^{63}$

Logically, however, one would think that the court might simply determine the validity of all claims and apportion the loss, with distribution amongst the nonoperators as the cestuis que trust made in proportion to their proved claims on a pro rata basis. The Ontario Court of Appeal in the Greymac Case ${ }^{64}$ has suggested that the rule in Clayton's Case ${ }^{65}$ should be confined strictly to bank-customer relationships and, as to application of the principle generally, stated: ${ }^{66}$

The foregoing indicates to me that the fundamental question is not whether the rule in Clayton's Case can properly be used for tracing purposes, as well as for loss allocation, but, rather, whether the rule should have any application at all to the resolution of problems connected with competing beneficial entitlements to a mingled trust fund where there have been withdrawals from the fund. From the perspective of basic concepts I do not think that it should. The better approach is that which recognizes the continuation, on a pro rata basis, of the respective property interests in the total amount of trust moneys or property available.

and also: ${ }^{67}$

While it might, possibly, be appropriate in some circumstances to recognize claims on the basis of a claimant's original contribution (but see Scott, The Law of Trusts, vol. 5, 3rd ed. (1967), at pp. 3647-52), I do not think that it is appropriate where the contributions to the mixed fund can be simply traced, as in the present case.

It is submitted that the principles established by this case would appropriately be applied in determination of the entitlement of non-operators to funds held in trust by the operator where such funds have been mixed and the total fund is insufficient to pay all, unless there is a compelling reason otherwise. However, no matter how the courts proceed in these circumstances, some non-operators may necessarily feel that they have been deprived of funds to which they believe they are entitled.

In apparent recognition of the decision in Sorrel, ${ }^{68}$ the 1988 Procedure provides that, notwithstanding that funds of a joint-operator have been co-mingled with the operator's funds, the moneys of a joint-operator advanced or paid to the operator, whether for the conduct of operations under the operating procedure or as proceeds from the sale of production, shall be deemed to be trust funds and shall be applied only to their intended use and shall in no way be deemed to be funds belonging to the operator, other than in its capacity as the non-operators' trustee. This will not, in and of itself, solve the tracing problems of mixed funds as outlined above.

\section{Expenditures Without Authorization}

Article III of the 1981 Procedure outlines the functions and duties of the operator. Clause 301 provides that the control and management of the exploration, development and operation of the joint lands for the joint account is delegated to

63. Devaynes v. Noble; Clayton's Case (1816), 1 Mer. 529, 35 E.R. 767 [hereinafter Clayton's Case]. See Waters, supra, note 62 at 1050.

64. Re Ontario Securities Commission and Greymac Credit Corp. (1987), 30 D.L.R. (4th) 1 (hereinafter Greymac].

65. Supra, note 63.

66. Supra, note 64 at 13.

67. Ibid. at 16.

68. Supra, note 57. 
the operator. While the provisions of Clause 301 remain essentially unchanged from the 1974 Procedure, the 1981 Procedure includes a further provision to the effect that the operator must consult with the non-operators from time to time with respect to decisions to be made for the exploration, development and operation of the joint-lands and must keep the non-operators informed with respect to operations planned or conducted for this joint account. However, there are no apparent sanctions or repercussions if he does not do so.

The 1974 Procedure provided in Clause 301 that the operator could not make an expenditure for any single undertaking for a total estimated cost in excess of $\$ 10,000.00$ without a written authority for expenditure ("AFE') from the jointoperators, unless this expenditure was considered to be necessary by reason of an event endangering life or property. Reliance on this qualification by the operator resulted in its being required to provide particulars of such events promptly to the joint-operators. The 1981 Procedure duplicates the concept of the 1974 Procedure but increases the specified non-AFE expenditure limit to $\$ 25,000.00$. Further, the 1981 Procedure provides that, subject to Clause 304 (which makes provisions for proper practices in operations) the operator is entitled to make such operating expenditures for the joint account as it considers necessary and prudent in order to carry on a good, workmanlike operation, provided that the operator does not exceed the $\$ 25,000.00$ limit for a single operation. There is potential for abuse in such situations in that the "operations" could be segmented into a series of minioperations such that advance approval by non-operators may technically not be required to complete the operation.

Clause 301 of the 1981 Procedure also provides that, notwithstanding the first part of this Clause, if, while conducting any single operation for the joint account which is covered by an AFE, the operator incurs or expects to incur expenditures in excess of the total amount authorized by the AFE for that operation plus $10 \%$ then the operator shall forthwith advise the non-operators and submit for their approval a supplementary AFE for the excess amount. The 1988 Procedure would amend this Clause by proposing that when expenses are in excess of the total amount authorized plus $10 \%$, the operator is to advise the non-operators in writing and thereafter provide estimates of current and cumulative costs incurred for the joint account pursuant to the AFE. These estimates are to be provided on a daily basis where practical, but in any event at intervals of not greater than ten days until the operation is complete.

When an AFE is prepared for an operation, it is usually made clear or it is at least understood by the industry that the amounts projected for expenditure are simply estimates for the operation, and the operator is not bound by these amounts. Once a non-operator approves an AFE, it will be liable for its share of all of the costs that may be incurred under that AFE, provided, of course, that these costs are for operations which the terms of that particular AFE have specifically authorized. This AFE system has often resulted in non-operators being responsible for costs greatly in excess of those anticipated.

Such was the situation that arose in the Renaissance case ${ }^{69}$ The parties had entered into an agreement to which it had appended the 1974 Procedure. An AFE which provided an estimate of the cost of drilling a test well was issued and approved. After drilling commenced problems arose which led to a massive cost

69. Supra, note 53 . 
overrun in the drilling and subsequent abandonment of the well. The court held that by approving the AFE, Metalore had given a written manifestation of its consent to participate in the undertaking to drill the test well. Once this consent was given, it became liable for its participating interest share of the total costs of the undertaking, which included both the costs of the drilling and the abandonment of the well. The Court held that Metalore was aware that the AFE provided only an estimate of the drilling costs and that once the AFE was signed, it had agreed to pay to Renaissance its share of the total cost of drilling and abandonment and was thus obligated to do so.

The Court noted in obiter dicta that the 1981 Procedure expressly requires a supplementary AFE to be approved when the costs incurred in a single operation are in excess of the total amount authorized by $10 \%$. However, since no such provision existed in the 1974 Procedure on which the AFE in question was based, this provision did not assist Metalore. As a result of this case, it is generally clear, at least under the 1974 Procedure, that a party who approves an AFE is bound to pay its share of the total costs of that operation, no matter how much greater than the original estimate the costs may be, provided that operation is properly described and is implemented as described. This conclusion is reached in apparent recognition of the inherent risks and uncertainties associated with the oil and gas business and the assumption that the operator has not agreed nor should it properly be found to have assumed all of the risks associated with the operation on its own. That is not the function of the operator, as it is also a joint-operator, and except in the specified circumstances, it is the joint-operators who properly and collectively share the risk of operations.

The additional provision in the 1981 Procedure in regard to amounts in excess of $10 \%$ was an apparent attempt to minimize the potential burden on joint-operators in such situations. Where this provision applies, joint-operators could argue that their total liabilities are not to be greater than the total amount authorized plus $10 \%$. However, such an application of this principle could impose an extremely onerous obligation on the operator. From a practical point of view, the $10 \%$ ceiling may, depending on the particular circumstances, be exceeded in a matter of hours or days. It may be virtually impossible for the operator to obtain supplementary AFE's for the additional expenditures contemplated without running the risk of having idling rigs on location accumulating further costs. In other words, the nature of the industry is such that often the paper cannot catch up to operations once commenced.

Clause 304 of the 1981 Procedure requires the operator to carry on all operations diligently, in a good, and workmanlike manner and in accordance with good oilfield practices. Even if it were possible to ascertain at a particular moment in time whether or not the $10 \%$ ceiling had been reached or was likely to be exceeded, it would certainly not be considered good oilfield practice to halt all operations prior to this point in time in order to obtain a supplementary AFE for the excess amounts. This is simply impractical and, as previously noted, would only serve to further increase costs. The operator may not be in a position to realize that the $10 \%$ ceiling has been reached or exceeded until the excess expenses had already been incurred and in most cases it would be highly impractical and inordinately expensive to suspend operations for the length of time necessary to obtain supplementary AFE's from each of the joint-operators involved. 
The result in the Renaissance case $\mathrm{e}^{70}$ does not indicate that the non-operators are without recourse in all situations. If it can be clearly demonstrated that the operator has exceeded the scope of the operation as described in the AFE, or has been negligent in its performance of the operation such that the costs incurred have far exceeded the level anticipated, a non-operator will be able to argue that it is not obligated to pay a share of these excess costs.

The Passburg Petroleums case ${ }^{71}$ is an example of how this situation can arise. Pursuant to a Participation Agreement dated September 10th, 1985 the Plaintiff Passburg was the operator for the joint account of itself, San Antonio Explorations Ltd. and D.W. Axford \& Associates Ltd. in the development and operation of a well at Morinville, Alberta. Pursuant to the Participation Agreement and the Plaintiff's incurring of costs, the Plaintiff claimed a sum of money alleged to be owed by the Defendants as their share of the costs of drilling the well not previously paid. The Plaintiff had issued an AFE to the Defendants which was approved. The AFE did not state that it was for the drilling of a directional well, which was done and clearly represented a considerable increase in the costs of drilling over a conventional well. The Plaintiffs submitted a supplemental AFE which the Defendants questioned and, in turn, refused to pay certain additional amounts claimed. The Plaintiff relied upon the Renaissance case ${ }^{72}$ as authority for the position that the Defendants were committed to the operation and to pay their allotted share of expenses no matter how incurred. The court rejected this argument. First, it stated that the operating procedure that was the subject of the Renaissance case ${ }^{73}$ the 1974 Procedure, contained different material requirements than the 1981 Procedure which applied in this case. The claim of the Plaintiffs was denied, although it is not clear from the decision whether the result would have been different had the Plaintiff drilled a conventional well which far exceeded the cost on the basis of the $10 \%$ cost over run rule described in the 1981 Procedure.

The proposed changes to the 1988 Procedure are intended to alleviate the heavy burden that the provisions in the 1981 Procedure may have inadvertently placed on the operator, although this is far from clear, while still taking into account the needs of the non-operators. Rather than requiring the operator to obtain a written AFE before any amounts in excess of $10 \%$ of the amount previously authorized are incurred, the operator is required to advise the non-operators in writing that the costs have exceeded the amount authorized plus $10 \%$. The operator must then provide estimates of the current excess costs and the cumulative costs incurred for the joint account pursuant to the AFE. Since these estimates are to be provided on a daily basis, or at least in intervals of not greater than ten days, the non-operators are kept apprised of the total costs for which they are potentially liable. Again, as with the 1974 Procedure and the 1981 Procedure, no clear statement is made as to the effect of the execution of an AFE. The practical result must necessarily be that the non-operators will be required to pay their full share of the costs of a well for which they have signed an AFE, unless the operator changes the nature of the operation to one which inherently represents a greater degree of risk or the operator is

70. Ibid.

71. Passburg Petroleums v. San Antonio Explorations Ld. and D. W. Axford \& Associates Ld., [1988] 57 Alta. L.R. (2d) 57 (Q.B.) [hereinafter Passburg Petroleums].

72. Supra, note 53.

73. Ibid. 
negligent in its performance of the operation. Proof of such facts could be difficult, although not likely insurmountable.

One of the primary concerns for the non-operators in such situations is to be able to predict the total amounts for which they are liable in order that they may arrange their finances to meet the costs. Non-operators will also be concerned to ensure that the operator does not incur unnecessary and excessive costs. However, while the value of predictability is certainly significant, it is recognized that the business of drilling wells is a highly speculative and extremely risky undertaking. It is impossible for anyone to predict all problems and obstacles which may increase the costs involved that may be encountered in drilling a particular well. Each of the joint-operators who hold a working interest in a well must be prepared to assume a proportionate share of the risk involved. To require the operator to be solely liable for cost overruns would impose a disproportionately large portion of that burden on one party. It must also be recognized in turn that the operator is in the best position to account for the costs that have been incurred and are continuing to be incurred during the operation. The 1988 Procedure attempts to balance opposing interests in spreading the risk among all working interest holders and in predicting and controlling the costs for which they are liable. The version of Clause 301 proposed for the 1988 Procedure provides that each party will be responsible for its share of cost overruns. However, when such overruns exceed the amount authorized by the AFE plus $10 \%$, the non-operators are to be kept informed on an ongoing basis of these excess costs in order that they may make the necessary adjustments to their financial planning.

The difficulty, from the point of view of the non-operators, with the proposed provisions for notice or advice pertaining to excess costs and expenses is that there are no sanctions on the operator for failing to comply with these requirements, such that they become of minimal potential benefit. A non-operator could argue that the operator is in breach of its obligations giving rise to a potential replacement of the operator pursuant to the provisions of Sub-paragraph 202(b)(ii), but the operator could easily defeat that challenge by simply providing the required information after the fact.

\section{Right to Audit or Protest Accounts}

Both the 1983 PASWC Accounting Procedure (the " 1983 Accounting Procedure") and the 1988 PASC Accounting Procedure (the "1988 Accounting Procedure") provide in Clause 108 that any non-operator has the right to audit the operator's accounts and records pertaining to the joint account for any calendar year, within the 24 month period next following the end of such calendar year, upon notice in writing to the operator and all other non-operators. It further provides that where two or more non-operators desire to conduct such an audit, they must make every reasonable effort to conduct joint or simultaneous audits in a manner which will result in a minimum of inconvenience to the operator. The 1983 Accounting Procedure provided that the cost of such audits were to be borne by all non-operators. The 1988 Accounting Procedure provides instead that the cost of all audits are to be shared by all non-operators where approvals are obtained from a majority interest of the non-operators. The majority interest is defined as two or more non-operators having interests totaling more than $50 \%$ of the interests in the joint property, excluding the operator's interest. This change reflects an attempt to resolve, at least 
in part, an apparent inequity in favour of the other non-operators who may benefit indirectly from an audit undertaken by one of their number. Some inequity remains, however, in that if an audit discloses that the non-operators have been overcharged by the operator, they have no recourse or ability to recover any of their audit costs, or even have the operator share in such costs. The 1983 Accounting Procedure provided that any claims of discrepancies disclosed by such audits were to be made in writing to the operator within two months of the completion of the audit. This provision has been eliminated from the 1988 Accounting Procedure.

Both the 1983 and the 1988 Accounting Procedures provide that the operator must respond to any claims of discrepancies within six months of receipt of such claims. The 1983 Procedure had provided by Clause 110 that, if the operator was unable to respond to the claims during this six month period, then one extension of three months could be allowed. The 1983 Accounting Procedure then provided that claims which remained unanswered after the six month period, and/or any additional three month extension, were to be credited forthwith to the joint account until they were resolved. The 1988 Accounting Procedure provides that the operator is to forthwith credit the joint account for the full amount of any unanswered claims upon the expiration of the six month period prescribed unless it has obtained the approval of the non-operators for a time extension. The length of such a time extension is not specified. The 1988 Accounting Procedure goes on to stipulate that, unless otherwise provided, the parties shall deal with any claims remaining unresolved after 12 months from the date of their initial filing. It is unclear what is meant by the term "deal with" or what happens if nothing is done. Perhaps the framers of the 1988 Accounting Procedure did not know or could not agree on the appropriate disposition of this matter. Claims which are resolved in favour of a non-operator are to be credited to that non-operator within 30 days of the date of the resolution of the claim.

The 1988 Accounting Procedure provides that the costs of audits of contractual services shall be for the joint account, with the approval of all of the parties. To the extent that the operator performs and charges the joint account for such audits, the operator's auditor's working papers and findings must be available for inspection and inquiry by the non-operators.

Both the 1983 and 1988 Accounting Procedures make provisions in Clause 107 for the non-operators to protest or question bills submitted to them by the operator. It is provided that the payment of any bills or requests for advances shall not prejudice the right of the non-operators to protest or question the correctness thereof. However, all bills and statements rendered to the non-operator during any calendar year shall conclusively be deemed to be true and correct after 26 months following the end of any such calendar year, unless within this 26 month period the non-operator takes written exception to these bills or statements and makes a claim on the operator for an adjustment. This deeming provision would not apply to fraud.

Paragraph 107(b) of the 1988 Accounting Procedure goes on to provide that if the non-operator or operator establishes that an error in the joint account existing in the 26 month period referred to above also existed previous to that period, then the operator must adjust the joint account retroactively to the inception of the error or to such point in time as agreed upon. These adjustments shall be subject to the non-operator's right to audit, as provided in Clause 108. Finally, it is stated that provisions of Clause 107 shall not prevent adjustments resulting from physical 
inventory of controllable materials, as provided for in Article $\mathrm{V}$ of the 1983 and 1988 Accounting Procedures.

\section{SEGREGATION OF JOINT LANDS}

Article XIII provides for the operation of lands which are segregated from the joint lands. The situation with which this Article is concerned is where any portion of the joint lands ceases to be owned by the parties to the operating procedure, by reason of the operation of any provision of that operating procedure, in the same percentages of interest as their participating interests, or ceases to be owned by all parties to the operating procedure. If this is the case, Clause 1301 provides that the parties acquiring the different percentages of interest in any portion of the former joint lands shall thereafter hold such lands as if they were parties to a separate operating procedure, the terms of which are identical to the original operating procedure, having regard only to the different ownership and percentages of ownership in those lands. Further, such severed portion of the joint lands shall cease to be "joint lands" under the original operating procedure. This situation can be the result of independent operations, ${ }^{74}$ disposition of partial interests only in the joint lands by a joint-operator that does not apply to the whole of the joint lands, or as a result of a farmout. In such circumstances the issue of operatorship must be dealt with and reference should be made to the earlier provisions of this paper.

If the operator is a party participating in the lands ceasing to be joint lands under Clause 1301, then it shall be the initial operator under the new operating procedure. The 1988 Procedure proposes that, rather than providing that the operator under the original operating procedure be the initial operator under the new operating procedure, the parties participating in the lands ceasing to be joint lands under Clause 1301 appoint one of their number to be the initial operator under the new operating procedure in accordance with the provisions of Article II thereof. No further changes to Clause 1301 are proposed for the 1988 Procedure at this time.

\section{RELATIONSHIP OF THE PARTIES}

Clause 1501 of the 1981 Procedure provides that the rights, duties, obligations and liabilities of the parties are to be several and not joint or collective and that the interests of the parties are to be held as tenants in common. It is specifically provided that nothing in the operating procedure is to be construed as creating a partnership, joint venture or association of any kind or as imposing on any party thereto any partnership duty, obligation or liability to any other party thereto. Clause 1501 remains unchanged from the 1974 Procedure, and no change is proposed in the 1988 Procedure.

Although Clause 1501 specifies that the parties are simply tenants in common, and not partners, it is important to keep in mind the decision of the Alberta Court of Appeal in the Sorrel case ${ }^{75}$ referred to above. Despite the provisions of Clause 1501, it is submitted that the operator will clearly be in the position of a

74. This will not be the case unless the non-participating parties have elected not to resume an active participation in the independent well when their right to so elect arises. If the election is negative, their interest in the well and the relevant lands is deemed to be terminated at that time.

75. Supra, note 57. 
fiduciary to the non-operators with respect to the management and administration of the joint lands and the marketing of production therefrom to the extent not taken in kind by the non-operators. As a fiduciary, the operator will be under strict fiduciary obligations to the non-operators and may be obligated to take into account their best interests, even where they do not coincide with the operator's. This potential trust or fiduciary relationship was recognized or at least alluded to in the past by Alberta Courts in several cases, ${ }^{76}$ but was never so clearly stated as in the Sorrel case, ${ }^{77}$ particularly insofar as the financial affairs of the venture were concerned.

The partnership issue raises an additional potential concern under the 1981 Procedure. To say in an agreement that a partnership does not exist is not sufficient in and of itself to achieve this result. If the operation under the 1981 Procedure is conducted as if it were a partnership, then it may be judicially characterized as such. Provisions such as the ability to take production in kind have been relied upon to address this issue. However, if all operations are unified, involving sales of production and the like, a partnership may nonetheless be found to exist. If so, the nonoperators are at risk of assuming increased liability as any partner has by law the ability to bind any other partner of the partnership. Therefore, non-operators should always conduct themselves in a manner that avoids this possible characterization.

\section{E. INDEPENDENT OPERATIONS}

If the parties simply cannot agree as to a strategy of development, location of wells or operatorship, and the other options of effecting a change of operatorship are not available under the 1981 Procedure, a non-operator may wish to propose an independent operation under Article X thereof. The wording of Clause 1002 clearly contemplates that the parties shall use their best efforts to consult with respect to exploration, development and operation of the joint lands, but that in any event a party may become a proposing party and give to the receiving parties a notice of operations. The notice should state the nature of the operation, the proposed location, the expected time of commencement, the purpose and estimated cost of operation (with appropriate detail, usually in the form of an AFE) and indicate whether it is a development well or an exploratory well or, if applicable, the extent to which it is both.

Each receiving party is to give notice to the proposing party within 30 days after receipt of the notice of operation whether that receiving party will participate in the operation. The notice period is reduced to 15 days if the well is to be drilled for the purpose of evaluating lands which the governmental authority has offered for public tender or which it is known will be so offered within 60 days after receipt of the operation notice, which, when applicable, is required to be included in such operation notice. In this Clause, the failure of a receiving party to give notice within the time provided is deemed to be notice that it will not participate.

Upon expiry of the relevant notice period, or as soon as all receiving parties have replied if earlier, the proposing party is to give notice to the participating parties

76. Act Oils Lid. v. Pacific Petroleums Lid., [1972] 4 W.W.R. 23 (Alta. Sup. Ct.), [1976] I W.W.R. 369 (Alta. Sup. Ct., App. Div.) and in Great Northern Petroleums \& Mines Ld. et al v. Merland Explorations Lid. et al, (1983) 25 Alta. L.R. (2d) 67 (Q.B.), (1985) 36 Alta. L.R. (2d) 97 (C.A.).

77. Supra, note 57. 
specifying how the costs, risks and benefits of the operation are to be shared which, in reference to Clause 1015, is to be in proportion to the respective participating interests, unless a receiving party has specified in its election to participate that it will participate only to the same percentage as its participating interest without taking up any of the non-participants' share. If such an election is made, the proposing party is required to notify the other participants promptly and determine whether they wish to assume, with the proposing party, the respective proportionate shares of the percentage not assumed by the party limiting its participation. Failure to respond to the proposing party's notice within 48 hours of receipt is deemed to be election not to assume any additional interest. ${ }^{78}$ The usual practice is for this latter election to be made in advance, and for the receiving parties to specify in their notice whether or not they are prepared to assume any additional percentage from the non-participating party's share not taken up by the participating parties.

It may be noted that the proposal and acceptance is in the nature of an option and as such the time limits must be strictly complied with. If a receiving party does not respond within the specified time, it will be excluded from the independent operations and be subject to the penalty described below. Article XXII deals with the giving of notices and one must clearly allow sufficient time to ensure that the notice of participation is actually received, or is deemed to be received. Although a proposing party may propose multiple operations, each requires a separate notice of operations, and there are other limitations that apply that need to be considered.

Clause 1003 of the 1981 Procedure provides that the proposing party may begin the operation immediately without waiting for receipt of all notices, but must do so not more than 60 days after the operation notice is deemed received by the receiving parties. If sufficient time is not allowed, the proposing party may issue a new notice of operations for the same operation within or after expiration of the 60 day period. This latter provision is obviously intended to address the situation where the proposing party cannot complete all necessary planning and preparation, including the obtaining of a well license, within the 60 day period. Clearly, a proposing party would not issue a notice in circumstances where road bans could prevent it from proceeding. While in most circumstances the 60 day period should be more than adequate, a problem arises with respect to sour gas wells which may require the holding of a public hearing by the Energy Resources Conservation Board (the "ERCB") which could extend the time past the 60 days.

A potential problem or concern from the point of view of the proposing party is that if it is required to issue a second operations notice for the same operation, the receiving parties who did not elect to participate when the first notice of operations was issued would appear again to have the opportunity to join the operation. This may be somewhat of an unfair advantage to the receiving parties, as they will have had additional time to evaluate the prospect of participating in the well and may well have additional valuable information about the performance or success of adjacent wells, if any. The proposing party loses some of the benefit of its aggressive, risk-taking approach in such circumstances.

A controversial provision is that set forth in Clause 1004 which provides that if the operator is a participating party, it is to carry out the operation. Again, it is possible for the non-operator to be defeated in its objective of assuming operations if this is the case. If the non-operator simply wanted development to proceed, this

78. Clause 1015, 1981 Procedure. 
would have been achieved. While the proposing party may have commenced the operation before knowing whether or not the operator is to be a participant, it is provided that upon becoming a participating party, the operator has the right to take over and carry out the operation. No time is specified for assumption by the operator of operations, although it may be implied that this should occur within a reasonable time. A provision often ignored is set forth in Clause 1004, which states that the operator for the independent operation (if the present operator does not participate) is to be selected by the participating parties from among them, i.e. it does not automatically fall to the proposing party. The 1981 Procedure does not deal with the conflict situation where the proposing party has commenced the operation and the participating parties have elected another of their membership to be operator for the operations. Enforcement of these provisions is clearly a problem because of timing. There will often be, in such circumstances, insufficient time to "force" the change in operator for the independent operation.

There are several practical problems associated with these provisions. First, the well could be drilled before the receiving parties have even made or are deemed to have made their election to participate. Does the operator in such circumstances still have the right to assume operatorship for the operations and what in turn would he be assuming? Secondly, how do the participating parties elect an operator for an operation they are not aware of? Thirdly, the proposing party will likely have obtained a well license and entered into a drilling contract and other contracts relating to services to be provided in respect of the operation. Some operators may have standing contractual obligations with such contractors that are given effect by the mere issuing of a purchase order or similar document. What then is to be assigned to the operator? If it is not assigned and the operator assumes conduct of the operation, who is at risk in terms of payment of the accounts?

The risk from the point of view of the non-operator who is a proposing party is that the operator may upon assumption of operatorship for the independent operation conduct the operation in a significantly different manner than the proposing party wished to, again perhaps defeating the purpose for the non-operator proposing the operation. Further, the operator might incur expenses that exceed what the proposing party might have been willing to incur. If for some reason the operator encountered financial difficulties, the non-operator who remains in privity of contract, i.e. with potential continuing obligations under the drilling or other contract, may find itself with a financial obligation far in excess of what it originally anticipated and over which it has exercised no control. The provisions of Clause 303 (which provide that the operator in its operations is an independent contractor) which may have otherwise protected the non-operator from direct liability as a noncontracting party, will not be available in this situation.

In view of the absence of a specific time for transfer of operatorship in the circumstances, the proposing non-operator party faced with an operator electing to assume operatorship may wish to resist permitting that to occur unless and until the operator has contractually assumed all of the obligations of the proposing party and the proposing party has been completely released from such obligations by the relevant contractors. It would appear that the non-operator would be on sound footing in this regard. If the proposing non-operator refused to give up operatorship, the operator would seem to have no alternative but to proceed with court action. For most wells that might be drilled, it would be difficult for such proceedings to be resolved before the well is completed or abandoned. 
The effect of independent operations on the legal interests of the parties to the relevant operating procedure is often misunderstood. The non-participating parties do not, at least initially, lose their interests in the joint lands by reason of their nonparticipation in the independent operation. Generally, the non-participating parties are charged with a production penalty pursuant to the provisions of Clause 1007. In the usual instance, the participating parties are entitled to recover $100 \%$ of the lessor's royalty, overriding royalties, costs of operating the well and the costs of equipping the well, with interest, plus an amount equal to a specified percentage of drilling costs and completion costs, usually $300 \%$ for a development well and $500 \%$ for an exploratory well.

The relevant operator is required to notify the non-participating parties of the fact of "deemed payout", and each has 30 days from receipt of such notice within which to elect to accept or refuse participation in the well and the attendant relevant formations and the production therefrom. If they do not elect, they will then be deemed to have forfeited any further right of participation in the well and the spacing unit lands insofar as the same relate to the producing formations and the production therefrom. If the non-participating party elects to participate, it will be included from the time of such "deemed payout" in the well at its original participating interest and will at that time again assume all associated rights and obligations. This is obviously not without risk, as further revenues could be low with abandonment and environmental clean-up costs high and perhaps even unforeseen. Although not specified, the participating parties will presumably continue to hold a proportionate share of any interest that the non-participating parties do not elect to take up. It may be noted that the original non-participating parties are deemed to have elected to take up the interest if they do not elect otherwise within the notice period.

Clause 1010 of the 1981 Procedure provides a further exception to the continuing interest of a non-participating party that could lead to forfeiture of an interest. If the independent operation is the drilling of a well which is required to preserve the interest of the parties in the joint lands, or a portion thereof, and the drilling of which is commenced during the final $1 / 6$ or the final 365 days (whichever is the shorter period) of the term of the title document which is due to terminate, the non-participating parties are required to assign to the participating parties, on a proportionate basis, all of the non-participating party's interest in and under the title documents insofar as they relate to the formations which would have otherwise terminated had the well not been drilled. The exception is where the nonparticipating parties have drilled or are in the process of drilling another well which would also have prevented termination. The amendments to this Clause proposed for the 1988 Procedure have significantly expanded this provision. Essentially, the result is not substantially different, and an in-depth analysis of the amendments is beyond the scope of this paper.

A provision of potential value to the participating parties, and to the non-operator who is initiating development in this manner, is the ability to deny the non-participating parties information respecting the operation undertaken for a specified period of time in a penalty situation and indefinitely in a forfeiture situation. This may be a useful sanction as the information from the well could give the participating parties a competitive advantage. If the operator has delayed development and is a non-participating party, the non-operator proposing the independent operation may well have achieved its objective. 


\section{SUMMARY AND CONCLUSIONS}

If a non-operator believes that an operator is insolvent or bankrupt, action should be initiated immediately by the non-operator in protection of its assets, and if advantageous, to effect a change of operatorship, in part for the purpose of avoiding any laches argument that might be made based on a failure to act promptly. Indeed, the non-operator must initiate proceedings in court if operatorship is not relinquished voluntarily by the operator. Consultation with other non-operators may also expedite the strategy. It is unlikely that an insolvent operator will be actively developing the joint lands, since its focus will be on its own survival, contrary to the very fundamental duties and obligations of an operator.

The non-operators may well find themselves in a situation where an insolvent operator seeks the protection of the $C C A A,{ }^{79}$ which may result in the change of operator being delayed for the duration of the resultant stay of proceedings. However, any stay that is granted pursuant to the $C C A A^{80}$ will be temporary, and the non-operators should be free to pursue their rights and remedies when the stay is exhausted, depending, of course, on any developments that occur in the interim period. The operator may cure its insolvency during the stay, or be disposed of as a going concern. It may, in any event, be possible to assert in such circumstances that the right to implementation of a change in operatorship has not been adversely affected by the stay. Depending on the particular circumstances, the non-operators should at least be afforded the opportunity to re-evaluate the issue of operatorship when the stay has terminated. However, one may expect that the Alberta Court of Appeal will ultimately need to resolve this particular issue. In any circumstances where it is proposed to remove the operator, a meeting should be called and a vote taken, as this will provide support for the process that will be involved and the Courts are apparently taking the view that positive action of this nature is a prerequisite to their involvement in forcing a change in operators.

If the operator is solvent and not otherwise in financial difficulty, but is not addressing the requirements of the non-operators, they may opt to issue a challenge of operator notice under the provisions of Clause 203 of the 1981 Procedure. The non-operator issuing the challenge notice must state that it is ready, able and willing to conduct operations for the joint account on more favorable terms and conditions than those under which the operation is currently being conducted. It may be implied in the circumstances that, to be more favourable, such terms and conditions must have a material economic or operational benefit for all of the joint-operators. However, it is important to understand that the operator may accept the challenge and continue operations on the basis set out in the challenge notice.

With respect to costs and expenses, Article V of the 1981 Procedure details the extensive provisions dealing with advances, cash calls and payments of accounts which affect the joint-operators. Many of the provisions favour the operator, and perhaps rightly so, as it is necessary to place the operator in a position where it can carry out the proposed operations for the joint account without delay and without the necessity of pursuing the non-operators to recover deficiencies. However, such provisions may be of concern for the non-operator in circumstances where the operator becomes insolvent or otherwise experiences financial difficulties. An

79. Supra, note 28.

80. Ibid. 
unscrupulous operator could apply such provisions to its advantage, clearly at the expense and risk of the non-operators.

There is no substitute for vigilance by the non-operators. If accounts are not being processed and paid or funds to which they are entitled are not being paid over to the non-operators within a reasonable time, the non-operators should conduct a diligent investigation. The accounting procedures do limit the time within which the non-operators may protest or question bills. In the absence of fraud, the time is relatively short. As well, the accounting procedures in use do not adequately deal with many of the problems that can arise, and the parties may wish to address these concerns up front.

The decision in the Sorrel case ${ }^{81}$ is of potential benefit to non-operators insofar as the operator is handling funds either advanced by them to the operator or received by the operator from other parties. However, the non-operators may still be faced with a tracing problem if there are either insufficient funds to meet obligations to them collectively or funds which cannot be ascertained with any degree of certainty as having initially been paid into the mixed or separate account in question.

The specific effect of execution of an AFE is somewhat undecided at the present time. However, it is clear from the decision in the Renaissance case ${ }^{82}$ that under the 1974 Procedure execution of an AFE constitutes a written manifestation of the consent by the non-operator to participate in the undertaking to drill the well and pay a proportionate share of the costs incurred. The exception will be the situation described in the Passburg Petroleums case ${ }^{83}$ which makes it clear that the operation must be carried out as it is outlined or the additional risk, if any, will be for the account of the operator.

Under the 1981 Procedure, a conclusion as to the effect of execution of an AFE is not as apparent, given the $10 \%$ overage rule. However, it is submitted that the practical effect must necessarily be the same. The nature and complexity of the oil and gas business is such that it is often not possible in the circumstances for the operator to obtain a supplemental AFE before the $10 \%$ overage is spent. As well, if the operator were to stop operations to permit such approval to be obtained, the costs could actually be even greater which in turn benefits no joint-operator. The proposed amendments to the 1988 Procedure appear to recognize this fact and propose a reporting and information process reflecting the responsibility of the jointoperators for their share of costs.

The 1981 Procedure, by its express terms, reflects an intention that the parties be tenants in common and not partners. If each party does take its share of production in kind, separately disposes of it, maintains its books and records separately and in general treats its interest as separate and apart from that of the other jointoperators, it may have achieved this objective. However, if the non-operators relinquish all of their rights, or the operations are undertaken in unity, they may be found to be in a partnership and as such bound by whatever actions may be taken by the operator, whether or not such actions were authorized.

The provisions for independent operations of the 1981 Procedure provide the most reliable course of action for non-operators to assure that the pace of development

81. Supra, note 57.
82. Supra, note 53.
83. Supra, note 71. 
of the joint lands is acceptable to them, short of resorting to the court process for removal of the operator. There are numerous uncertainties with respect to the provisions for independent operations as presently drafted, particularly in selection of the operator for the independent operation. Moreover, there are practical problems involved, in that a proposing party could easily have drilled the well before the other parties had knowledge of that fact, which would appear contrary to the intention of the framers of the operating procedure. 